\title{
Common fixed points of generalized rational contractions on a closed ball in partial metric spaces
}

\author{
Muhammad Nazam ${ }^{\mathrm{a}}$, Muhammad Arshad ${ }^{\mathrm{b}}$, Choonkil Park ${ }^{\mathrm{c}, *}$, Sungsik Yun ${ }^{\mathrm{d}}$ \\ a Department of Mathematics, International Islamic University Islamabad, Pakistan. \\ ${ }^{b}$ Department of Mathematics and Statistics, International Islamic University, H-10, Islamabad, Pakistan. \\ ${ }^{c}$ Research Institute for Natural Sciences, Hanyang University, Seoul 04763, Republic of Korea. \\ ${ }^{d}$ Department of Financial Mathematics, Hanshin University, Gyeonggi-do 18101, Republic of Korea.
}

Communicated by M. De La Sen

\begin{abstract}
The notion of generalized contractions of rational type on a closed ball is introduced and used to establish some common fixed point theorems for two, three and four mappings in complete ordered partial metric spaces. These results improve several well-known, primary and conventional results. We give an example to illustrate the main idea of our results that there are mappings which have only fixed points inside or on the closed ball instead of whole space. (C)2017 All rights reserved.
\end{abstract}

Keywords: Common fixed point, closed ball, generalized contraction, partial metric space. 2010 MSC: $47 \mathrm{H} 09,47 \mathrm{H} 10,54 \mathrm{H} 25$.

\section{Introduction and preliminaries}

A partial metric on a nonempty set $X$ is a function $p: X \times X \rightarrow[0, \infty)$ such that

$\left(p_{1}\right) x=y \Leftrightarrow p(x, x)=p(x, y)=p(y, y) ;$

$\left(\mathrm{p}_{2}\right) \mathrm{p}(\mathrm{x}, \mathrm{x}) \leqslant \mathrm{p}(\mathrm{x}, \mathrm{y})$;

$\left(\mathrm{p}_{3}\right) \mathrm{p}(\mathrm{x}, \mathrm{y})=\mathrm{p}(\mathrm{y}, \mathrm{x})$;

$\left(p_{4}\right) p(x, y) \leqslant p(x, z)+p(z, y)-p(z, z)$.

Partial metrics were introduced in [16] as a generalization of the notion of metric to allow non-zero self distance for the purpose of modeling partial objects in reasoning about data flow networks. The self distance $p(x, x)$ is to be understood as a quantification of the extent to which $x$ is unknown. A partial

\footnotetext{
*Corresponding author

Email addresses: nazim.phdma47@iiu.edu.pk (Muhammad Nazam), marshadzia@iiu.edu.pk (Muhammad Arshad), baak@hanyang.ac.kr (Choonkil Park), ssyun@hs.ac.kr (Sungsik Yun)

doi:10.22436/jnsa.010.10.12
} 
metric space is a pair $(X, p)$ such that $X$ is a nonempty set and $p$ is a partial metric on $X$. Matthews [16] proved an analogue of Banach's fixed point theorem in partial metric spaces. After this remarkable fixed point theorem, many authors took interest in partial metric spaces and its topological properties and established many well-known fixed point results successfully (see $[1,2,5,6,11]$ ).

The study of fixed point theorems on contractions involving rational expression was coined by Dass and Gupta [10]. In [17], Karapinar et al. gave partial metric version of theorem presented by Dass and Gupta in [10]. Following Dass and Gupta, Almeida et al. [3] established some fixed point theorems on contractions of rational type which generalize theorem presented by Dass and Gupta [10].

In this paper we work on more general contractive conditions of rational type and present several fixed point theorems for one, two, three and four mappings in partial metric spaces. These results can be applied to show the existence of equilibrium points of a dynamical system within or on the magnetic field.

Consistent with $[8,9,12-16]$, the following definitions and results will be needed in the sequel. Throughout this paper, we denote $(0, \infty)$ by $\mathbb{R}^{+},[0, \infty)$ by $\mathbb{R}_{0}^{+},(-\infty,+\infty)$ by $\mathbb{R}$ and set of natural numbers by $\mathbb{N}$.

Let $T: X \rightarrow X$ be a mapping. A point $x \in X$ is called a fixed point of $T$ if $x=T(x)$. Let $x_{0}$ be an arbitrarily chosen point in $X$. Define a sequence $\left\{x_{n}\right\}$ in $X$ by a simple iterative method given by

$$
x_{n+1}=T\left(x_{n}\right), \quad \text { where } n \in\{0,1,2, \cdots\} .
$$

Such a sequence is called a Picard iterative sequence and its convergence plays a very important role in proving an existence of a fixed point of a mapping $T$.

Each partial metric $p$ on $X$ induces a $T_{0}$ topology $\tau(p)$ on $X$ which has as a base the family of open balls $\left\{B_{p}(x, \varepsilon): x \in X, \varepsilon>0\right\}$, where $B_{p}(x, \varepsilon)=\{y \in X: p(x, y)<p(x, x)+\varepsilon\}$ for all $x \in X$ and $\varepsilon>0$. Also $\overline{\mathrm{B}\left(\mathrm{x}_{0}, r\right)}=\{y \in X: p(x, y) \leqslant p(x, x)+\varepsilon\}$ is a closed ball in $(X, p)$.

It is clear that $p(x, y)=0$ implies $x=y$ by $\left(P_{1}\right)$ and $\left(P_{2}\right)$. But if $x=y$, then $p(x, y)$ may not be 0 . A basic example of a partial metric space is the pair $\left(R_{0}^{+}, p\right)$, where $p(x, y)=\max \{x, y\}$ for all $x, y \in R_{0}^{+}$.

Example 1.1 ([16]). If $X=\{[a, b]: a, b \in R, a \leqslant b\}$ then $p([a, b],[c, d])=\max \{b, d\}-\min \{a, c\}$ defines a partial metric $p$ on $X$.

Definition 1.2 ([16]). Let $(X, p)$ be a partial metric space. Then we have the following.

(a) A sequence $\left\{x_{n}\right\}$ in $(X, p)$ converges to a point $x \in X$ if and only if $\lim _{n \rightarrow \infty} p\left(x_{n}, x\right)=p(x, x)$.

(b) A sequence $\left\{x_{n}\right\}$ in $(X, p)$ is called a Cauchy sequence if $\lim _{n \rightarrow m \rightarrow \infty} p\left(x_{n}, x_{m}\right)$ exists and is finite.

(c) $(X, p)$ is said to be complete, if for a Cauchy sequence $\left\{x_{n}\right\}$ in $X$, there exists some $z \in X$ such that

$$
\lim _{n, m \rightarrow \infty} p\left(x_{n}, x_{m}\right)=\lim _{n \rightarrow \infty} p\left(x_{n}, z\right)=p(z, z) .
$$

(d) If $(X, p)$ is a partial metric space, then $p_{s}(x, y)=2 p(x, y)-p(x, x)-p(y, y), x, y \in X$, is a metric on $X$.

Lemma 1.3 ([16]). Let $(X, \mathrm{p})$ be a partial metric space.

(a) $\left\{x_{n}\right\}$ is a Cauchy sequence in $(X, p)$ if and only if it is a Cauchy sequence in the metric space $\left(X, p_{s}\right)$.

(b) $(X, p)$ is complete if and only if the metric space $\left(X, p_{s}\right)$ is complete. Furthermore, $\lim _{n \rightarrow \infty} p_{s}\left(x_{n}, z\right)=0$ if and only if $p(z, z)=\lim _{n \rightarrow \infty} p\left(x_{n}, z\right)=\lim _{n, m \rightarrow \infty} p\left(x_{n}, x_{m}\right)$.

Definition 1.4 ([4]). Let $X$ be a nonempty set. Then $(X, \preceq, p)$ is called an ordered partial metric space if

(i) $p$ is a partial metric on $X$; and 
(ii) $\preceq$ is a partial order on $X$.

Definition 1.5. Let $(X, \preceq)$ be a partial ordered set. Then $x, y \in X$ are called comparable if $x \preceq y$ or $y \preceq x$ holds. We define $\nabla=\{(x, y) \in X \times X \mid x$ and $y$ are comparable $\}$.

Definition 1.6. Let $X$ be a nonempty set and let $T, f: X \rightarrow X$ be mappings. A point $y \in X$ is called a point of coincidence of $T$ and $f$ if there exists a point $x \in X$ such that $y=T(x)=f(x)$. The mappings $T, f$ are said to be weakly compatible if they commute at their coincidence point (i.e., $\operatorname{Tf}(x)=f T(x)$ whenever $T(x)=f(x))$.

We require the following lemmas.

Lemma 1.7 ([13]). Let $\mathrm{X}$ be a nonempty set and $\mathrm{f}: \mathrm{X} \rightarrow \mathrm{X}$ a mapping. Then there exists a subset $\mathrm{E} \subset \mathrm{X}$ such that $f(E)=f(X)$ and $f: E \rightarrow X$ is one to one.

Lemma 1.8 ([7]). Let $\mathrm{X}$ be a nonempty set and let $\mathrm{S}, \mathrm{T}, \mathrm{f}: \mathrm{X} \rightarrow \mathrm{X}$ have a unique point of coincidence $v$ in $\mathrm{X}$. If $(\mathrm{S}, \mathrm{f})$ and $(\mathrm{T}, \mathrm{f})$ are weakly compatible, then $\mathrm{S}, \mathrm{T}$ and $\mathrm{f}$ have a unique common fixed point.

\section{Common fixed point theorems for two mappings}

This section contains some common fixed point theorems for a pair of generalized contractions of rational type on a closed ball in an ordered partial metric space. We begin with the following definition.

Definition 2.1. Let $(X, \preceq, p)$ be a complete ordered partial metric space and $S_{g}, T_{g}: X \rightarrow X$ be two mappings. We say that $\left(S_{g}, T_{g}\right)$ is a pair of generalized contractions of rational type on a closed ball if they satisfy the following condition:

$$
p\left(S_{g}(x), T_{g}(y)\right) \leqslant \lambda \max \left\{p(x, y), \frac{p\left(x, S_{g}(x)\right) p\left(y, T_{g}(y)\right)}{1+p(x, y)}, \frac{p\left(x, S_{g}(x)\right) p\left(y, T_{g}(y)\right)}{1+p\left(S_{g}(x), T_{g}(y)\right)}\right\}
$$

for all $(x, y) \in\left(\overline{\mathrm{B}\left(\mathrm{x}_{0}, r\right)} \times \overline{\mathrm{B}\left(\mathrm{x}_{0}, \mathrm{r}\right)}\right) \cap \nabla, \lambda \in[0,1)$ and for any $x_{0} \in X$.

Theorem 2.2. Let $(X, \preceq, p)$ be a complete ordered partial metric space and $S_{g}, T_{g}: X \rightarrow X$ be two mappings such that the following conditions hold.

(1) $\left(S_{g}, T_{g}\right)$ is a pair of generalized contractions of rational type on a closed ball;

(2) $S_{g}, T_{g}$ are nonincreasing mappings such that $x_{0} \succeq S_{g}\left(x_{0}\right)$;

(3) $p\left(x_{0}, S_{g}\left(x_{0}\right)\right) \leqslant(1-\lambda)\left[r+p\left(x_{0}, x_{0}\right)\right]$.

Then there exists a point $x^{*}$ such that $p\left(x^{*}, x^{*}\right)=0$. Also if for a nonincreasing sequence $\left\{x_{n}\right\}$ in $\overline{\mathrm{B}\left(x_{0}, r\right)},\left\{x_{n}\right\} \rightarrow u$ implies that $\mathrm{u} \preceq \mathrm{x}_{\mathrm{n}}$, then $\mathrm{x}^{*}=\mathrm{S}_{\mathrm{g}}\left(\mathrm{x}^{*}\right)=\mathrm{T}_{\mathrm{g}}\left(\mathrm{x}^{*}\right)$. Moreover, $\mathrm{x}^{*}$ is unique if any two points $\mathrm{x}, \mathrm{y}$ in $\overline{\mathrm{B}\left(\mathrm{x}_{0}, \mathrm{r}\right)}$ are comparable.

Proof. Let $x_{0}$ be any initial point in $X$ and choose a point $x_{1}$ in $X$ such that $x_{1}=S_{g}\left(x_{0}\right)$. Since $S_{g}\left(x_{0}\right) \preceq x_{0}$, $\left(x_{1}, x_{0}\right) \in \nabla$ and let $x_{2}=T_{g}\left(x_{1}\right)$. Since $x_{1} \succeq T_{g}\left(x_{1}\right),\left(x_{2}, x_{1}\right) \in \nabla$. Continuing this process and having chosen $x_{n}$ in $X$ such that

$$
x_{2 i+1}=S_{g}\left(x_{2 i}\right) \text { and } x_{2 i+2}=T_{g}\left(x_{2 i+1}\right), \quad \text { where } i=0,1,2, \cdots,
$$

we obtain $\left(x_{n+1}, x_{n}\right) \in \nabla$ for all $n \in N$. We claim that $x_{n} \in \overline{B\left(x_{0}, r\right)}$ for all $n \in N$. By assumption (3), we have

$$
p\left(x_{0}, S_{g}\left(x_{0}\right)\right) \leqslant(1-\lambda)\left[r+p\left(x_{0}, x_{0}\right)\right]
$$




$$
\leqslant r+p\left(x_{0}, x_{0}\right)
$$

It follows that $x_{1} \in \overline{\mathrm{B}\left(x_{0}, r\right)}$. Let $x_{2}, \cdots, x_{j} \in \overline{\mathrm{B}\left(x_{0}, r\right)}$ for some $j \in N$. If $j=2 i+1$, then $\left(x_{2 i+1}, x_{2 i}\right) \in$ $\left(\overline{\mathrm{B}\left(\mathrm{x}_{0}, r\right)} \times \overline{\mathrm{B}\left(\mathrm{x}_{0}, r\right)}\right) \cap \nabla$, where $i=0,1,2, \cdots \frac{j-1}{2}$. By $(2.1)$, we obtain

$$
\begin{aligned}
p\left(x_{2 i+1}, x_{2 i+2}\right) & =p\left(S_{g}\left(x_{2 i}\right), T_{g}\left(x_{2 i+1}\right)\right) \\
& \leqslant \lambda \max \left\{\begin{array}{l}
p\left(x_{2 i}, x_{2 i+1}\right), \frac{p\left(x_{2 i}, S_{g}\left(x_{2 i}\right)\right) p\left(x_{2 i+1}, T_{g}\left(x_{2 i+1}\right)\right)}{1+p\left(x_{2 i}, x_{2 i+1}\right)}, \\
\frac{p\left(x_{2 i}, S_{g}\left(x_{2 i}\right)\right) p\left(x_{2 i+1}, T_{g}\left(x_{2 i+1}\right)\right)}{1+p\left(S_{g}\left(x_{2 i}\right), T_{g}\left(x_{2 i+1}\right)\right)}
\end{array}\right\} \\
& =\lambda \max \left\{\begin{array}{l}
p\left(x_{2 i}, x_{2 i+1}\right), \frac{p\left(x_{2 i}, x_{2 i+1}\right) p\left(x_{2 i+1}, x_{2 i+2}\right)}{1+p\left(x_{2 i}, x_{2 i+1}\right)}, \\
\frac{p\left(x_{2 i}, x_{2 i+1}\right) p\left(x_{2 i+1}, x_{2 i+2}\right)}{1+p\left(x_{2 i+1}, x_{2 i+2}\right)}
\end{array}\right\} \\
& \leqslant \lambda \max \left\{p\left(x_{2 i}, x_{2 i+1}\right), p\left(x_{2 i+1}, x_{2 i+2}\right)\right\},
\end{aligned}
$$

which implies that

$$
\begin{aligned}
p\left(x_{2 i+1}, x_{2 i+2}\right) & \leqslant \lambda p\left(x_{2 i}, x_{2 i+1}\right) \\
& \leqslant \lambda^{2} p\left(x_{2 i-1}, x_{2 i}\right) \leqslant \cdots \leqslant \lambda^{2 i+1} p\left(x_{0}, x_{1}\right) .
\end{aligned}
$$

If $j=2 i+2$, then $x_{1}, x_{2}, \cdots, x_{j} \in \overline{\mathrm{B}\left(x_{0}, r\right)}$ and $\left(x_{2 i+2}, x_{2 i+1}\right) \in\left(\overline{B\left(x_{0}, r\right)} \times \overline{B\left(x_{0}, r\right)}\right) \cap \nabla, \quad\left(i=0,1,2, \cdots, \frac{j-2}{2}\right)$. We obtain

$$
p\left(x_{2 i+2}, x_{2 i+3}\right) \leqslant \lambda^{2 i+2} p\left(x_{0}, x_{1}\right) .
$$

Thus from (2.2) and (2.3), we have

$$
p\left(x_{j}, x_{j+1}\right) \leqslant \lambda^{j} p\left(x_{0}, x_{1}\right), \quad \text { for some } j \in N .
$$

Now consider

$$
\begin{aligned}
p\left(x_{0}, x_{j+1}\right) & \leqslant p\left(x_{0}, x_{1}\right)+\cdots+p\left(x_{j}, x_{j+1}\right)-\left[p\left(x_{1}, x_{1}\right)+\cdots+p\left(x_{j}, x_{j}\right)\right] \\
& \leqslant p\left(x_{0}, x_{1}\right)+\cdots+\lambda^{j} p\left(x_{0}, x_{1}\right) \quad(\text { by }(2.4)) \\
& =p\left(x_{0}, x_{1}\right)\left[1+\cdots+\lambda^{j-1}+\lambda^{j}\right] \\
& \leqslant(1-\lambda)\left[r+p\left(x_{0}, x_{0}\right)\right] \frac{\left(1-\lambda^{j+1}\right)}{1-\lambda} \\
& \leqslant r+p\left(x_{0}, x_{0}\right),
\end{aligned}
$$

which gives $x_{j+1} \in \overline{\mathrm{B}\left(x_{0}, r\right)}$. Hence $x_{n} \in \overline{\mathrm{B}\left(x_{0}, r\right)}$ for all $n \in N$. Also $\left(x_{n+1}, x_{n}\right) \in\left(\overline{\mathrm{B}\left(x_{0}, r\right)} \times \overline{\mathrm{B}\left(x_{0}, r\right)}\right) \cap \nabla$ for all $n \in N$. It implies that

$$
p\left(x_{n}, x_{n+1}\right) \leqslant \lambda^{n} p\left(x_{0}, x_{1}\right), \quad \forall n \in N
$$

From $\left(\mathrm{p}_{2}\right)$, we have

$$
\begin{aligned}
p\left(x_{n}, x_{n}\right) & \leqslant p\left(x_{n}, x_{n+1}\right) \\
& \leqslant \lambda^{n} p\left(x_{0}, x_{1}\right) \longrightarrow 0, \text { as } n \rightarrow \infty .
\end{aligned}
$$

Moreover,

$$
\begin{aligned}
p_{s}\left(x_{n+1}, x_{n}\right) & =2 p\left(x_{n}, x_{n+1}\right)-p\left(x_{n}, x_{n}\right)-p\left(x_{n+1}, x_{n+1}\right) \\
& \leqslant 2 p\left(x_{n}, x_{n+1}\right) \\
& \leqslant 2 \lambda^{n} p\left(x_{0}, x_{1}\right) . \quad(\text { by }(2.5))
\end{aligned}
$$


Thus by the triangular inequality, we get

$$
\begin{aligned}
p_{s}\left(x_{n+k}, x_{n}\right) & \leqslant p_{s}\left(x_{n+k}, x_{n+k-1}\right)+\cdots+p_{s}\left(x_{n+1}, x_{n}\right) \\
& \leqslant 2 \lambda^{n+k-1} p\left(x_{0}, x_{1}\right)+\cdots+2 \lambda^{n} p\left(x_{0}, x_{1}\right) \\
& =2 \lambda^{n} p\left(x_{0}, x_{1}\right)\left[\lambda^{k-1}+\lambda^{k-2}+\cdots+1\right] \\
& \leqslant 2 \lambda^{n} p\left(x_{0}, x_{1}\right) \frac{\left(1-\lambda^{k}\right)}{1-\lambda} \rightarrow 0, \quad \text { as } n \rightarrow \infty
\end{aligned}
$$

Hence the sequence $\left\{x_{n}\right\}$ is a Cauchy sequence in $\left(\overline{B\left(x_{0}, r\right)}, p_{s}\right)$. By Lemma $1.3,\left\{x_{n}\right\}$ is a Cauchy sequence in $\left(\overline{B\left(x_{0}, r\right)}, p\right)$. Therefore, there exists a point $x^{*} \in \overline{B\left(x_{0}, r\right)}$ with $\lim _{n \rightarrow \infty} x_{n}=x^{*}$. Also $\lim _{n \rightarrow \infty} p_{s}\left(x_{n}, x^{*}\right)=0$. Now by Lemma 1.3 and (2.6), we have

$$
p\left(x^{*}, x^{*}\right)=\lim _{n \rightarrow \infty} p\left(x_{n}, x^{*}\right)=\lim _{n, m \rightarrow \infty} p\left(x_{n}, x_{m}\right)=0 .
$$

In addition, by the given assumption, $x_{n} \rightarrow x^{*}$ as $n \rightarrow \infty$ implies that $\left(x^{*}, x_{n}\right) \in \nabla$. Also,

$$
\left(x^{*}, x_{2 n+1}\right) \in\left(\overline{\mathrm{B}\left(\mathrm{x}_{0}, \mathrm{r}\right)} \times \overline{\mathrm{B}\left(\mathrm{x}_{0}, \mathrm{r}\right)}\right) \cap \nabla .
$$

Then

$$
\begin{aligned}
& p\left(x^{*}, S_{g}\left(x^{*}\right)\right) \leqslant p\left(x^{*}, x_{2 n+2}\right)+p\left(x_{2 n+2},\right.\left.S_{g}\left(x^{*}\right)\right)-p\left(x_{2 n+2}, x_{2 n+2}\right) \\
& \leqslant p\left(x^{*}, x_{2 n+2}\right)+\lambda \max \left\{\begin{array}{l}
p\left(x^{*}, x_{2 n+1}\right), \\
\frac{p\left(x^{*}, S_{g}\left(x^{*}\right)\right) p\left(x_{2 n+1}, T_{g}\left(x_{2 n+1}\right)\right)}{1+p\left(x^{*}, x_{2 n+1}\right)}, \\
\frac{p\left(x^{*}, S_{g}\left(x^{*}\right)\right) p\left(x_{2 n+1}, T_{g}\left(x_{2 n+1}\right)\right)}{1+p\left(S_{g}\left(x^{*}\right), T_{g}\left(x_{2 n+1}\right)\right)}
\end{array}\right\} .
\end{aligned}
$$

On taking limit $n \rightarrow \infty$ and by using (2.5) and (2.8), we obtain

$$
p\left(x^{*}, S_{g}\left(x^{*}\right)\right) \leqslant 0,
$$

and $x^{*}=S_{g}\left(x^{*}\right)$.

Similarly, by using

$$
p\left(x^{*}, T_{g}\left(x^{*}\right)\right) \leqslant p\left(x^{*}, x_{2 n+1}\right)+p\left(x_{2 n+1}, T_{g}\left(x^{*}\right)\right)-p\left(x_{2 n+1}, x_{2 n+1}\right),
$$

we can show that $x^{*}=T_{g}\left(x^{*}\right)$. Hence $S_{g}$ and $T_{g}$ have a common fixed point in $\overline{B\left(x_{0}, r\right)}$. In order to show the uniqueness of fixed point, suppose on the contrary that $y$ is another point in $\bar{B}\left(x_{0}, r\right)$ such that $y=S_{g}(y)=T_{g}(y)$. Since $x^{*} \preceq y$,

$$
\begin{aligned}
p\left(x^{*}, y\right) & =p\left(S_{g}\left(x^{*}\right), T_{g}(y)\right) \\
& \leqslant \lambda \max \left\{\begin{array}{l}
p\left(x^{*}, y\right), \frac{p\left(x^{*}, S_{g}\left(x^{*}\right)\right) p\left(y, T_{g}(y)\right)}{1+p\left(x^{*}, y\right)} \\
\frac{p\left(x^{*}, S_{g}\left(x^{*}\right)\right) p\left(y, T_{g}(y)\right)}{1+p\left(S_{g}\left(x^{*}\right), T_{g}(y)\right)}
\end{array}\right\} \\
& \leqslant \lambda \max \left\{p\left(x^{*}, y\right), \frac{p\left(x^{*}, x^{*}\right) p(y, y)}{1+p\left(x^{*}, y\right)}, \frac{p\left(x^{*}, x^{*}\right) p(y, y)}{1+p\left(x^{*}, y\right)}\right\} \\
& \leqslant \lambda p\left(x^{*}, y\right),
\end{aligned}
$$

which implies $p\left(x^{*}, y\right)=0$. Now, using the properties $\left(p_{1}\right)$ and $\left(p_{2}\right)$, we have $x^{*}=y$, as desired. 
In Theorem 2.2, the assumption (3) is imposed to restrict the contractive condition (2.1) only for $x, y$ in $\overline{\mathrm{B}\left(\mathrm{x}_{0}, \mathrm{r}\right)}$. The following example explains Theorem 2.2 and describes the importance of restrictions imposed in Theorem 2.2.

Example 2.3. Let $X=R_{0}^{+}$be endowed with order $x \preceq y$ if $p(x, x) \leqslant p(y, y)$ and let $p: X \times X \rightarrow R_{0}^{+} \cup\{0\}$ be the complete ordered partial metric on $X$ defined by $p(x, y)=\max \{x, y\}$.

$$
S_{g}(x)= \begin{cases}\frac{x}{13}, & \text { if } x \in[0,1], \\ x-\frac{4}{7}, & \text { if } x \in(1, \infty),\end{cases}
$$

and

$$
\mathrm{T}_{g}(x)= \begin{cases}\frac{x}{26}, & \text { if } x \in[0,1], \\ x-\frac{3}{5}, & \text { if } x \in(1, \infty) .\end{cases}
$$

Clearly, $S_{g}$ and $T_{g}$ are nonincreasing mappings. Take $\lambda=\frac{3}{7}, x_{0}=\frac{1}{2}, r=\frac{1}{2}$. Then we have $p\left(x_{0}, x_{0}\right)=$ $\max \left\{\frac{1}{2}, \frac{1}{2}\right\}=\frac{1}{2}$ and $\overline{\mathrm{B}\left(\mathrm{x}_{0}, \mathrm{r}\right)}=[0,1]$. Also

$$
\begin{gathered}
(1-\lambda)\left[r+p\left(x_{0}, x_{0}\right)\right]=\left(1-\frac{3}{7}\right)\left[\frac{1}{2}+\frac{1}{2}\right]=\frac{4}{7} \\
p\left(x_{0}, S_{g}\left(x_{0}\right)\right)=p\left(\frac{1}{2}, S_{g} \frac{1}{2}\right)=p\left(\frac{1}{2}, \frac{1}{26}\right)=\max \left\{\frac{1}{2}, \frac{1}{26}\right\}=\frac{1}{2}<\frac{4}{7} .
\end{gathered}
$$

Without loss of generality we can assume that $x \geqslant y$ and for $x, y \in(1, \infty)$,

$$
\begin{aligned}
p\left(S_{g}(x), T_{g}(y)\right) & =\max \left\{x-\frac{4}{7}, y-\frac{3}{5}\right\}=x-\frac{4}{7} \\
& \geqslant \frac{3}{7} \max \left\{x, \frac{x y}{1+x}+\frac{x y}{\frac{3}{7}+x}\right\}, \\
p\left(S_{g}(x), T_{g}(y)\right) & \geqslant \lambda \max \left\{\begin{array}{l}
p(x, y), \frac{p\left(x, S_{g}(x)\right) p\left(y, T_{g}(y)\right)}{1+p(x, y)} \\
\frac{p\left(x, S_{g}(x)\right) p\left(y, T_{g}(y)\right)}{1+p\left(S_{g}(x), T_{g}(y)\right)}
\end{array}\right\} .
\end{aligned}
$$

So the contractive condition does not hold on $X$. Now if $x, y \in \overline{B\left(x_{0}, r\right)}$, then

$$
\begin{aligned}
p\left(S_{g}(x), T_{g}(y)\right) & =\max \left\{\frac{x}{13}, \frac{y}{26}\right\}=\frac{1}{13} \max \{x, 0.5 y\} \\
& \leqslant \frac{3}{7}[x] \\
& =\frac{3}{7} \max \left\{x, \frac{x y}{1+x}+\frac{x y}{\frac{x}{13}+1}\right\} \\
& =\lambda \max \left\{\begin{array}{l}
p(x, y), \frac{p\left(x, S_{g}(x)\right) p\left(y, T_{g}(y)\right)}{1+p(x, y)}, \\
\frac{p\left(x, S_{g}(x)\right) p\left(y, T_{g}(y)\right)}{1+p\left(S_{g}(x), T_{g}(y)\right)}
\end{array}\right\} .
\end{aligned}
$$

Therefore, all the conditions of Theorem 2.2 are satisfied. Moreover, $x=0$ is a common fixed point of $S_{g}$ and $T_{g}$.

Corollary 2.4. Let $(X, \preceq, p)$ be a complete ordered partial metric space, $x_{0}, x, y \in X, r>0$ and $S_{g}: X \rightarrow X$ be a nonincreasing mapping. Suppose that there exists $\lambda \in[0,1)$ such that the following conditions hold: 
(1) $S_{g}$ is a generalized contraction of rational type on a closed ball;

(2) $S_{g}$ is a nonincreasing mapping such that $x_{0} \succeq S_{g}\left(x_{0}\right)$;

(3) $p\left(x_{0}, S_{g}\left(x_{0}\right)\right) \leqslant(1-\lambda)\left[r+p\left(x_{0}, x_{0}\right)\right]$.

Then there exists a point $x^{*}$ such that $\mathrm{p}\left(x^{*}, x^{*}\right)=0$. Also, if for a nonincreasing sequence $\left\{x_{n}\right\}$ in $\overline{\mathrm{B}\left(x_{0}, r\right)},\left\{x_{n}\right\} \rightarrow u$ implies that $\mathrm{u} \preceq \mathrm{x}_{\mathrm{n}}$, then $\mathrm{x}^{*}=\mathrm{S}_{\mathrm{g}}\left(\mathrm{x}^{*}\right)$. Moreover, $\mathrm{x}^{*}$ is unique if any two points $\mathrm{x}, \mathrm{y}$ in $\overline{\mathrm{B}\left(\mathrm{x}_{0}, \mathrm{r}\right)}$ are comparable.

Proof. Setting $T_{g}=S_{g}$ in Theorem 2.2, we get a unique point $x^{*} \in \overline{\mathrm{B}\left(x_{0}, r\right)}$ such that $x^{*}=S_{g}\left(x^{*}\right)$.

The following result relaxes the condition (3) of Theorem 2.2 but imposes the condition (2.1) for all comparable elements in the whole space $X$.

Corollary 2.5. Let $(X, \preceq, p)$ be a complete ordered partial metric space and $S_{g}, T_{g}: X \rightarrow X$ be two nonincreasing mappings. Suppose that there exists $\lambda \in[0,1)$ such that the following condition holds for all $(x, y) \in \nabla$

$$
p\left(S_{g}(x), T_{g}(y)\right) \leqslant \lambda \max \left\{\begin{array}{l}
p(x, y), \frac{p\left(x, S_{g}(x)\right) p\left(y, T_{g}(y)\right)}{1+p(x, y)}, \\
\frac{p\left(x, S_{g}(x)\right) p\left(y, T_{g}(y)\right)}{1+p\left(S_{g}(x), T_{g}(y)\right)}
\end{array}\right\} .
$$

Then, there exists a point $x^{*}$ such that $p\left(x^{*}, x^{*}\right)=0$. Also, if for a nonincreasing sequence $\left\{x_{n}\right\}$ in $X,\left\{x_{n}\right\} \rightarrow u$ implies that $\mathrm{u} \preceq x_{\mathrm{n}}$, then $\mathrm{x}^{*}=\mathrm{S}_{\mathrm{g}}\left(\mathrm{x}^{*}\right)=\mathrm{T}_{\mathrm{g}}\left(\mathrm{x}^{*}\right)$.

Corollary 2.6. Let $(X, p)$ be a complete partial metric space and $S_{g}, T_{g}: X \rightarrow X$ be two mappings such that

$$
p\left(S_{g}(x), T_{g}(y)\right) \leqslant \lambda \max \left\{\begin{array}{l}
p(x, y), \frac{p\left(x, S_{g}(x)\right) p\left(y, T_{g}(y)\right)}{1+p(x, y)} \\
\frac{p\left(x, S_{g}(x)\right) p\left(y, T_{g}(y)\right)}{1+p\left(S_{g}(x), T_{g}(y)\right)}
\end{array}\right\}
$$

for all $x, y \in \overline{\mathrm{B}\left(\mathrm{x}_{0}, \mathrm{r}\right)}$. Then, there exists a point $\mathrm{x}^{*}$ such that $\mathrm{p}\left(\mathrm{x}^{*}, \mathrm{x}^{*}\right)=0$ and $\mathrm{x}^{*}=\mathrm{S}_{\mathrm{g}}\left(\mathrm{x}^{*}\right)=\mathrm{T}_{\mathrm{g}}\left(\mathrm{x}^{*}\right)$. Moreover, $x^{*}$ is a unique common fixed point of $S_{g}$ and $T_{g}$.

\section{Common fixed point theorems for three and four mappings}

Now we apply Theorem 2.2 to obtain a unique common fixed point of three mappings on a closed ball in complete partial ordered metric space. The technique and style of our proof is quite smart and innovative.

Theorem 3.1. Let $(X, \preceq, p)$ be an ordered partial metric space, $x_{0}, x, y \in X, r>0$ and $f$ be a nonincreasing mapping on $\mathrm{X}$ such that $\mathrm{S}_{\mathrm{g}}(\mathrm{X}) \cup \mathrm{T}_{\mathrm{g}}(\mathrm{X}) \subset \mathrm{f}(\mathrm{X}), \overline{\mathrm{B}\left(\mathrm{f}\left(\mathrm{x}_{0}\right), \mathrm{r}\right)} \subseteq \mathrm{f}(\mathrm{X})$ and $\left(\mathrm{T}_{\mathrm{g}}(\mathrm{X}), \mathrm{f}(\mathrm{x})\right),\left(\mathrm{S}_{\mathrm{g}}(\mathrm{X}), \mathrm{f}(\mathrm{x})\right) \in \nabla$. Assume that $\mathrm{S}_{\mathrm{g}}$ and $\mathrm{T}_{\mathrm{g}}$ are self-mappings which satisfy the following condition

$$
p\left(S_{g}(x), T_{g}(y)\right) \leqslant \lambda \max \left\{\begin{array}{l}
p(f(x), f(y)), \frac{p\left(f(x), S_{g}(x)\right) p\left(f(y), T_{g}(y)\right)}{1+p(f(x), f(y))}, \\
\frac{p\left(f(x), S_{g}(x)\right) p\left(f(y), T_{g}(y)\right)}{1+p\left(S_{g}(x), T_{g}(y)\right)}
\end{array}\right\}
$$

for all $(\mathrm{f}(\mathrm{x}), \mathrm{f}(\mathrm{y})) \in\left(\overline{\mathrm{B}\left(\mathrm{f}\left(\mathrm{x}_{0}\right), \mathrm{r}\right)} \times \overline{\mathrm{B}\left(\mathrm{f}\left(\mathrm{x}_{0}\right), \mathrm{r}\right)}\right) \cap \nabla, \lambda \in[0,1)$. In addition,

$$
p\left(f\left(x_{0}\right), T_{g}\left(x_{0}\right)\right) \leqslant(1-\lambda)\left[r+p\left(f\left(x_{0}\right), f\left(x_{0}\right)\right)\right] .
$$

If for a nonincreasing sequence $\left\{x_{n}\right\}$ in $\overline{\mathrm{B}\left(f\left(x_{0}\right), r\right)},\left\{x_{n}\right\} \rightarrow u$ implies that $u \preceq x_{n}, f(X)$ is a complete subspace of $X$ and $\left(\mathrm{S}_{g}, \mathrm{f}\right)$ and $\left(\mathrm{T}_{\mathrm{g}}, \mathrm{f}\right)$ are weakly compatible, then $\mathrm{S}_{\mathrm{g}}, \mathrm{T}_{\mathrm{g}}$ and $\mathrm{f}$ have a common fixed point $\mathrm{f}(\mathrm{z})$ in $\overline{\mathrm{B}\left(\mathrm{f}\left(\mathrm{x}_{0}\right), \mathrm{r}\right)}$ with $p(f(z), f(z))=0$. 
Proof. Due to Lemma 1.7, there exists $E \subset X$ such that $f(E)=f(X)$ and $f: E \rightarrow X$ is one-to-one. Now since $S_{g}(X) \cup T_{g}(X) \subset f(X)$, we define two mappings $\phi, \psi: f(E) \rightarrow f(E)$ by $\phi(f x)=S_{g}(x)$ and $\psi(f x)=T_{g}(x)$, respectively. Since $f$ is one-to-one on $E, \phi, \psi$ are well-defined. Since $\left(S_{g}(x), f(x)\right) \in \nabla$ implies that $(\phi(f x), f x) \in \nabla$ and $\left(T_{g}(x), f(x)\right) \in \nabla$ implies that $(\psi(f x), f x) \in \nabla, \phi$ and $\psi$ are nonincreasing. Now $f\left(x_{0}\right) \in \overline{B\left(f\left(x_{0}\right), r\right)} \subseteq f(X)$ and so $f\left(x_{0}\right) \in f(X)$. Let $y_{0}=f\left(x_{0}\right)$. Choose a point $y_{1}$ in $f(X)$ such that $y_{1}=\psi\left(y_{0}\right)$. Since $\psi\left(y_{0}\right) \preceq y_{0},\left(y_{1}, y_{0}\right) \in \nabla$ and let $y_{2}=\phi\left(y_{1}\right)$. Now $\phi\left(y_{1}\right) \preceq y_{1}$ gives $\left(y_{2}, y_{1}\right) \in \nabla$. Continuing this process and having chosen $y_{n}$ in $f(X)$ such that

$$
y_{2 i+1}=\psi\left(y_{2 i}\right) \text { and } y_{2 i+2}=\phi\left(y_{2 i+1}\right), \quad \text { where } i=0,1,2, \cdots,
$$

then $\underline{y}_{2 i+1}=\psi\left(y_{2 i}\right) \preceq y_{2 i}$ implies $\left(y_{2 i+1}, y_{2 i}\right) \in \nabla$. By a similar argument of Theorem 2.2 , we can get $y_{n} \in \overline{B\left(f\left(x_{0}\right), r\right)}$. Due to (3.2), we have

$$
p\left(f\left(x_{0}\right), \psi\left(f\left(x_{0}\right)\right)\right) \leqslant(1-\lambda)\left[r+p\left(f\left(x_{0}\right), f\left(x_{0}\right)\right)\right] .
$$

By (3.1), $(f(x), f(y)) \in\left(\overline{B\left(f\left(x_{0}\right), r\right)} \times \overline{B\left(f\left(x_{0}\right), r\right)}\right) \cap \nabla$ and

$$
p(\phi(f(x)), \psi(f(y))) \leqslant \lambda \max \left\{\begin{array}{l}
p(f(x), f(y)), \frac{p(f(x), \phi(f(x))) p(f(y), \psi(f(y)))}{1+p(f(x), f(y))}, \\
\frac{p(f(x), \phi(f(x))) p(f(y), \psi(f(y)))}{1+p(\phi(f(x)), \psi(f(y)))}
\end{array}\right\}
$$

Since $f(X)$ is a complete space, all the conditions of Theorem 2.2 are satisfied, and we deduce that there exists a common fixed point $f(z) \in \overline{B\left(f\left(x_{0}\right), r\right)}$ of $\phi$ and $\psi$. Also $p(f(z), f(z))=0$. Now $f(z)=\phi(f z)=\psi(f z)$ or $f(z)=S_{g}(z)=T_{g}(z)=f(z)$. Thus $f(z)$ is the point of coincidence of $S_{g}, T_{g}$ and $f$. Let $v \in \overline{B\left(f\left(x_{0}\right), r\right)}$ be another point of coincidence of $f, S_{g}$ and $T_{g}$. Then, there exists $u \in \overline{B\left(f\left(x_{0}\right), r\right)}$ such that $v=f(u)=S_{g}(u)=$ $T_{g}(u)$, which implies that $f(u)=\phi(f(u))=\psi(f(u))$. This contradicts the fact that $f(z) \in \overline{B\left(f\left(x_{0}\right), r\right)}$ is a unique common fixed point of $\phi$ and $\psi$. Hence $v=f(z)$. Thus $S_{g}, T_{g}$ and $f$ have a unique point of coincidence $f(z) \in \overline{B\left(f\left(x_{0}\right), r\right)}$. Now since $\left(S_{g}, f\right)$ and $\left(T_{g}, f\right)$ are weakly compatible, by Lemma $1.8, f(z)$ is a unique common fixed point of $S_{g}, T_{g}$ and $f$.

Now we can apply Corollary 2.5 to obtain a unique common fixed point result of three mappings in a complete partial ordered metric space.

Corollary 3.2. Let $(X, \preceq, p)$ be an ordered partial metric space and $\mathrm{f}$ be a nonincreasing mapping on $\mathrm{X}$ such that $S_{g}(X) \cup T_{g}(X) \subset f(X)$ and $\left(T_{g}(x), f(x)\right),\left(S_{g}(x), f(x)\right) \in \nabla$. Assume that $S_{g}, T_{g}$ are self-mappings on $X$ satisfying the following contractive condition

$$
p\left(S_{g}(x), T_{g}(y)\right) \leqslant \lambda \max \left\{\begin{array}{l}
p(f(x), f(y)), \frac{p\left(f(x), S_{g}(x)\right) p\left(f(y), T_{g}(y)\right)}{1+p(f(x), f(y))}, \\
\frac{p\left(f(x), S_{g}(x)\right) p\left(f(y), T_{g}(y)\right)}{1+p\left(S_{g}(x), T_{g}(y)\right)}
\end{array}\right\}
$$

for all $(\mathrm{f}(\mathrm{x}), \mathrm{f}(\mathrm{y})) \in \nabla$ and $\lambda \in[0,1)$. Assume that, for a nonincreasing sequence $\left\{x_{n}\right\}$ in $f(X),\left\{x_{n}\right\} \rightarrow u$ implies that $u \preceq x_{n}$ and $f(X)$ is a complete subspace of $X$. In addition, if $\left(S_{g}, f\right)$ and $\left(T_{g}, f\right)$ are weakly compatible, then $S_{g}, T_{g}$ and $f$ have a unique common fixed point $f(z)$ in $f(X)$ with $\mathrm{p}(\mathrm{f}(z), f(z))=0$.

In the following theorem, we establish the existence of a unique common fixed point of four mappings on a closed ball in a complete partial metric space.

Theorem 3.3. Let $(X, p)$ be a partial metric space, $x_{0}, x, y \in X, r>0$ and $f$ be self-mapping on $X$ such that $\mathrm{S}_{\mathrm{g}}(\mathrm{X}), \mathrm{T}_{\mathrm{g}}(\mathrm{X}) \subset \mathrm{f}(\mathrm{X})=\phi(\mathrm{X})$ and $\overline{\mathrm{B}\left(\mathrm{f}\left(\mathrm{x}_{0}\right), \mathrm{r}\right)} \subseteq \mathrm{f}(\mathrm{X})$. Assume that $\mathrm{S}_{\mathrm{g}}$ and $\mathrm{T}_{\mathrm{g}}$ are self-mappings which satisfy the following conditions

$$
p\left(S_{g}(x), T_{g}(y)\right) \leqslant \lambda \max \left\{\begin{array}{l}
p(f(x), \phi(y)), \frac{p\left(f(x), S_{g}(x)\right) p\left(\phi(y), T_{g}(y)\right)}{1+p(f(x), \phi(y))}, \\
\frac{p\left(f(x), S_{g}(x)\right) p\left(\phi(y), T_{g}(y)\right)}{1+p\left(S_{g}(x), T_{g}(y)\right)}
\end{array}\right\}
$$


for all $\mathrm{f}(\mathrm{x}), \mathrm{f}(\mathrm{y}) \in \overline{\mathrm{B}\left(\mathrm{f}\left(\mathrm{x}_{0}\right), \mathrm{r}\right)}$, where $\lambda \in[0,1)$ and

$$
p\left(f\left(x_{0}\right), S_{g}\left(x_{0}\right)\right) \leqslant(1-\lambda)\left[r+p\left(f\left(x_{0}\right), f\left(x_{0}\right)\right)\right]
$$

If $\mathrm{f}(\mathrm{X})$ is a complete subspace of $\mathrm{X}$ and $\left(\mathrm{S}_{\mathrm{g}}, \mathrm{f}\right)$ and $\left(\mathrm{T}_{\mathrm{g}}, \phi\right)$ are weakly compatible, then $\mathrm{S}_{\mathrm{g}}, \mathrm{T}_{\mathrm{g}}$, $\mathrm{f}$ and $\phi$ have a unique common fixed point $\mathrm{f}(z)$ in $\overline{\mathrm{B}\left(\mathrm{f}\left(\mathrm{x}_{0}\right), \mathrm{r}\right)}$ with $\mathrm{p}(\mathrm{f}(z), \mathrm{f}(z))=0$.

Proof. Due to Lemma 1.7, there exist $E_{1}, E_{2} \subset X$ such that $f\left(E_{1}\right)=f(X)=\phi(X)=\phi\left(E_{2}\right), f: E_{1} \rightarrow$ $X, \phi: E_{2} \rightarrow X$ are one to one. Now define the mappings $\Pi, \Theta: f\left(E_{1}\right) \rightarrow f\left(E_{1}\right)$ by $\Pi(f(x))=S_{g}(x)$ and $\Theta(g(x))=T_{g}(x)$, respectively. Since $f, \phi$ are one to one on $E_{1}$ and $E_{2}$ respectively, the mappings $\Pi, \Theta$ are well-defined. Since $f\left(x_{0}\right) \in \overline{B\left(f\left(x_{0}\right), r\right)} \subseteq f(X), f\left(x_{0}\right) \in f(X)$. Let $y_{0}=f\left(x_{0}\right)$. Choose a point $y_{1}$ in $f(X)$ such that $y_{1}=\Pi\left(y_{0}\right)$ and let $y_{2}=\Theta\left(y_{1}\right)$. Continuing this process and having chosen $y_{n}$ in $f(X)$ such that

$$
y_{2 i+1}=\Pi\left(y_{2 i}\right) \text { and } y_{2 i+2}=\Theta\left(y_{2 i+1}\right), \quad \text { where } i=0,1,2, \cdots,
$$

and by a similar argument of Theorem 2.2, we can get $y_{n} \in \overline{B\left(f\left(x_{0}\right), r\right)}$. Also by (3.4), we have

$$
p\left(f\left(x_{0}\right), \Pi\left(f\left(x_{0}\right)\right)\right) \leqslant(1-\lambda)\left[r+p\left(f\left(x_{0}\right), f\left(x_{0}\right)\right)\right] .
$$

By (3.3), for $f(x), \phi(y) \in \overline{B\left(f\left(x_{0}\right), r\right)}$, we have

$$
p(\Pi(f(x)), \Theta(\phi(y))) \leqslant \lambda \max \left\{\begin{array}{l}
p(f(x), \phi(y)), \frac{p(f(x), \Pi(f(x))) p(\phi(y), \Theta(\phi(y)))}{1+p(f(x), \phi(y))}, \\
\frac{p(f(x), \Pi(f(x))) p(\phi(y), \Theta(\phi(y)))}{1+p(\Pi(f(x)), \Theta(\phi(y)))}
\end{array}\right\} .
$$

Since $f(X)$ is a complete space, all the conditions of Corollary 3.2 are satisfied, and we deduce that there exists a unique common fixed point $f(z) \in \overline{\mathrm{B}\left(f\left(x_{0}\right), r\right)}$ of $\Pi$ and $\Theta$. Further $\Pi$ and $\Theta$ have no fixed point other than $f(z)$. Also $p(f(z), f(z))=0$. Now $f(z)=\Pi(f(z))=\Theta(f(z))$ or $f(z)=S_{g}(z)=f(z)$. Thus $f(z)$ is a point of coincidence of $f$ and $S_{g}$. Let $w \in \overline{\mathrm{B}\left(f\left(x_{0}\right), r\right)}$ be another point of coincidence of $S_{g}$ and $f$. Then, there exists $u \in \overline{B\left(f\left(x_{0}\right), r\right)}$ such that $w=f(u)=S_{g}(u)$, which implies that $f(u)=\Pi(f(u))$. This contradicts the fact that $f(z) \in \overline{\mathrm{B}\left(f\left(x_{0}\right), r\right)}$ is a unique fixed point of $\Pi$. Hence $w=f(z)$. Thus $S_{g}$ and $f$ have a unique point of coincidence $f(z) \in \overline{B\left(f\left(x_{0}\right), r\right)}$. Since $\left(S_{g}, f\right)$ are weakly compatible, by Lemma 1.8, $f(z)$ is a unique common fixed point of $S_{g}$ and $f$. Since $f(X)=\phi(X)$, there exists $v \in X$ such that $f(z)=\phi(v)$. Now we have

$$
\Pi(f(z))=\Theta(f(z))=f(z) \Rightarrow \Pi(\phi(v))=\Theta(\phi(v))=\phi(v) \Rightarrow T_{g}(v)=\phi(v)
$$

and thus $\phi(v)$ is a point of coincidence of $T_{g}$ and $\phi$. Now

$$
\mathrm{T}_{\mathrm{g}}(\mathrm{x})=\phi(\mathrm{x}) \Rightarrow \Theta(\phi(x))=\phi(x) .
$$

This implies that $\phi(v)=\phi(x)$. Since $T_{g}$ and $\phi$ are weakly compatible, we obtain a unique common fixed point $\phi(v)$ for $T_{g}$ and $\phi$. But $\phi(v)=f(z)$. Thus, $S_{g}, T_{g}, \phi$ and $f$ have a unique common fixed point $f(z) \in \overline{\mathrm{B}\left(\mathrm{f}\left(\mathrm{x}_{0}\right), \mathrm{r}\right)}$.

\section{Acknowledgment}

C. Park was supported by Basic Science Research Program through the National Research Foundation of Korea funded by the Ministry of Education, Science and Technology (NRF-2017R1D1A1B04032937).

\section{References}

[1] T. Abdeljawad, Meir-Keeler $\alpha$-contractive fixed and common fixed point theorems, Fixed Point Theory Appl., 2013 (2013), 10 pages. 1

[2] T. Abdeljawad, E. Karapınar, K. Taş, Existence and uniqueness of a common fixed point on partial metric spaces, Appl. Math. Lett., 24 (2011), 1900-1904. 1

[3] Á. Almeida, A. F. Roldán-López-de-Hierro, K. Sadarangani, On a fixed point theorem and its application in dynamic programming, Appl. Anal. Discrete Math., 9 (2015), 221-244. 1 
[4] I. Altun, A. Erduran, Fixed point theorems for monotone mappings on partial metric spaces, Fixed Point Theory Appl., 2011 (2011), 10 pages. 1.4

[5] I. Altun, S. Romaguera, Characterizations of partial metric completeness in terms of weakly contractive mappings having fixed point, Appl. Anal. Discrete Math., 6 (2012), 247-256. 1

[6] I. Altun, F. Sola, H. Simsek, Generalized contractions on partial metric spaces, Topology Appl., 157 (2010), $2778-2785$. 1

[7] M. Arshad, A. Azam, P. Vetro, Some common fixed point results in cone metric spaces, Fixed Point Theory Appl., 2009 (2009), 11 pages. 1.8

[8] M. Bukatin, R. Kopperman, S. Matthews, H. Pajoohesh, Partial metric spaces, Amer. Math. Monthly, 116 (2009), 708-718. 1

[9] M. A. Bukatin, S. Y. Shorina, Partial metrics and co-continuous valuations, Foundations of software science and computation structures, Lisbon, (1998), Lecture Notes in Comput. Sci., Springer, Berlin, 1378 (1998), 125-139. 1

[10] B. K. Dass, S. Gupta, An extension of Banach contraction principle through rational expression, Indian J. Pure Appl. Math., 6 (1975), 1455-1458. 1

[11] Í. M. Erhan, E. Karapinar, D. Türkoğlu, Different types Meir-Keeler contractions on partial metric spaces, J. Comput. Anal. Appl., 14 (2012), 1000-1005. 1

[12] T. Gnana Bhaskar, V. Lakshmikantham, Fixed point theorems in partially ordered metric spaces and applications, Nonlinear Anal., 65 (2006), 1379-1393. 1

[13] R. H. Haghi, S. Rezapour, N. Shahzad, Some fixed point generalizations are not real generalizations, Nonlinear Anal., 74 (2011), 1799-1803. 1.7

[14] R. Kannan, Some results on fixed points, Bull. Calcutta Math. Soc., 60 (1968), 71-76.

[15] K. N. Leibovic, The principle of contraction mapping in nonlinear and adaptive control systems, IEEE Trans. Automatic Control, 9 (1964), 393-398.

[16] S. G. Matthews, Partial metric topology, Papers on general topology and applications, Flushing, NY, (1992), Ann. New York Acad. Sci., New York Acad. Sci., New York, 728 (1994), 183-197. 1, 1.1, 1.2, 1.3

[17] H. K. Nashine, E. Karapinar, Fixed point results in orbitally complete partial metric spaces, Bull. Malays. Math. Sci. Soc., 36 (2013), 1185-1193. 1 